\title{
Network dynamics of drought-induced tipping cascades in the Amazon rainforest
}

\section{Nico Wunderling ( $\nabla$ nico.wunderling@pik-potsdam.de )}

Potsdam Institute for Climate Impact Research https://orcid.org/0000-0002-3566-323X

\section{Arie Staal}

Stockholm Resilience Centre https://orcid.org/0000-0001-5409-1436

\section{Boris Sakschewski}

Potsdam Institute for Climate Impact Research

\section{Marina Hirota}

Federal University of Santa Catarina https://orcid.org/0000-0002-1958-3651

Obbe Tuinenburg

Utrecht University https://orcid.org/0000-0001-6895-0094

\section{Jonathan Donges}

Potsdam Institute for Climate Impact Research https://orcid.org/0000-0001-5233-7703

\section{Henrique Barbosa}

University of São Paulo https://orcid.org/0000-0002-4027-1855

\section{Ricarda Winkelmann}

Potsdam Institute for Climate Impact Research https://orcid.org/0000-0003-1248-3217

\section{Article}

Keywords: Tipping elements, Amazon rainforest, drought-induced tipping cascades

Posted Date: September 21st, 2020

DOI: https://doi.org/10.21203/rs.3.rs-71039/v1

License: (c) (i) This work is licensed under a Creative Commons Attribution 4.0 International License.

Read Full License 


\title{
Network dynamics of drought-induced tipping cascades in the Amazon rainforest
}

\author{
Nico Wunderling, ${ }^{1,2,3^{*}}$ Arie Staal, ${ }^{4,5}$ Boris Sakschewski, ${ }^{1}$ \\ Marina Hirota, ${ }^{6,7}$ Obbe A. Tuinenburg, ${ }^{4,5}$ Jonathan F. Donges ${ }^{1,4}$, \\ Henrique M. J. Barbosa ${ }^{8,9^{* \dagger}}$ \& Ricarda Winkelmann ${ }^{1,2^{* \dagger}}$ \\ ${ }^{1}$ Earth System Analysis, Potsdam Institute for Climate Impact Research (PIK), \\ Member of the Leibniz Association, 14473 Potsdam, Germany \\ ${ }^{2}$ Institute of Physics and Astronomy, University of Potsdam, 14476 Potsdam, Germany \\ ${ }^{3}$ Department of Physics, Humboldt University of Berlin, 12489 Berlin, Germany \\ ${ }^{4}$ Stockholm Resilience Centre, Stockholm University, Stockholm, SE-10691, Sweden \\ ${ }^{5}$ Department of Environmental Science, Copernicus Institute of Sustainable \\ Development, Utrecht University, Utrecht, 3512 JE, The Netherlands \\ ${ }^{6}$ Department of Physics, Federal University of Santa Catarina, Florianópolis, \\ 88040-900-SC, Brazil \\ ${ }^{7}$ Department of Plant Biology, University of Campinas, Campinas, 13083-970-SP, Brazil \\ ${ }^{8}$ Instituto de Física, Universidade de São Paulo, São Paulo, 05508-090-SP, Brazil \\ ${ }^{9}$ Physics Department, University of Maryland Baltimore County, Baltimore, MD 21250, USA
}

${ }^{*}$ Correspondences should be addressed to: nico.wunderling@pik-potsdam.de, hbarbosa@if.usp.br or ricarda.winkelmann@ pik-potsdam.de

${ }^{\dagger}$ These authors jointly supervised this study. 
Tipping elements are nonlinear subsystems of the Earth system that can potentially abruptly and irreversibly shift if environmental change occurs. Among these tipping elements is the Amazon rainforest, which is threatened by anthropogenic activities and increasingly frequent droughts. Here, we assess how extreme deviations from climatological rainfall regimes may cause local forestsavanna transitions that cascade through the coupled forest-climate system. We develop a dynamical network model to uncover the role of atmospheric moisture recycling in such tipping cascades. We account for the heterogeneity in critical thresholds of the forest caused by adaptation to local climatic conditions. Our results reveal that, despite this adaptation, increased dry-season intensity may trigger tipping events particularly in the southeastern Amazon. Moisture recycling is responsible for one-fourth of the tipping events. If the rate of climate change exceeds the adaptive capacity of some parts of the forest, secondary effects through moisture recycling may exceed this capacity in other regions, increasing the overall risk of tipping across the Amazon rainforest. 
The Amazon rainforest is the most biodiverse terrestrial ecosystem and plays a fundamental role in regulating the global climate $\frac{1223}{}$. However, human-induced impacts and climatic extremes are increasingly threatening the forest's integrity and the services it provides ${ }^{45[6}$. Furthermore, changes might not be gradual, but could be rather abrupt due to nonlinear interactions, as suggested by simulation studies $\frac{788}{\text {, data-based approaches }} \stackrel{910}{ }$, conceptual models $\frac{1112}{12}$ and longterm experiments 13 . Parts of the Amazon rainforest may be bistable, meaning that they could tip to an alternative state of low tree cover $\frac{910}{10}$. Indeed, the Amazon has been suggested to be a tipping element in the Earth system $\frac{14}{14}$ and might be at risk of approaching or exceeding its tipping point ${ }^{4 / 15 \mid 16}$. This tipping point can be crossed when the conditions become too dry. Potentially, this could occur due to declining average precipitation levels or with increasing dry spells and severity of extreme droughts $17 / 18 / 19 \mid 20$. Changes in precipitation regimes are already occurring over southern Amazonian regions where the length of the dry season has been in-

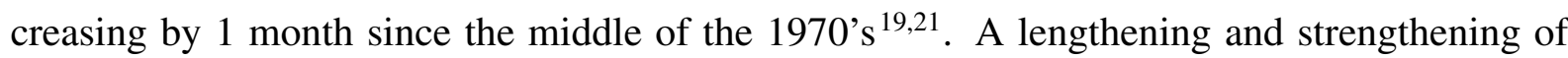
the dry season in southern Amazonia has also been confirmed by other model studies from CMIP5 simulations as well as empirical precipitation models 2223 . In regions where dry periods last longer than four months, this would severely impact vital functions of the Amazon rainforest $^{4[22}$.

The Amazon is not a uniform forest as trees can adapt to local climatic conditions, for instance through variable rooting strategies $24 \mid 25$. This can lead to different absolute forest mortality thresholds with respect to precipitation and drought conditions on local to regional scales. Forest adaptation can therefore ensure that plants will operate close to their physiological maximum, but this creates vulnerabilities when the climate changes faster than the ecosystem can respond to ${ }^{26}$. In case of this inadequate response, regional climatic changes can be accelerated by the forest itself, because trees contribute to precipitation regionally. 
Trees recycle part of the precipitated moisture through continental moisture recycling $27 \mid 28$. They do so by extracting water from deeper soil levels and releasing it through their leaves (transpiration) and by directly re-evaporating precipitation from their leaves (interception evaporation). The total amount of moisture recycling accounts for up to half of the precipitation over the Amazon basin and moisture is recycled up to six times $28 \mid 29[30 \mid 31$. Thus, the rainforest depends on itself, and precipitation and evapotranspiration cycles promote cascading forest growth 29 . The positive interplay between the forest and regional precipitation implies that local perturbations can propagate through the system via reduced moisture recycling. In other words, the Amazon rainforest can be considered a network of local tipping elements that are connected via moisture recycling.

The loss of the moisture flows among different parts of the Amazon as a result of state transitions can increase vulnerabilities remotely and exacerbate tipping events since the forest would then no longer be adapted to the prevailing conditions ${ }^{32[33}$. Recent severe droughts such as in 2005 and 2010 already impacted the rainforest ${ }^{34 \mid 35}$, but without causing major state transitions of vegetation cover. While the rainforest might be able to withstand incidental droughts, the adaptations may become insufficient when such droughts become the new climate normal. Indeed, it has been projected that the major drought event of 2005 might occur more frequently, up to nine out of ten years by $2060^{36 / 37}$. By reconstructing the dynamical moisture recycling networks from the recent past, we can study how climate change may exceed the adaptation capacity of the forest and subsequently trigger tipping points that cascade through the Amazon rainforest system.

Here, we integrate for the first time in a dynamical network model the tipping behaviour of 
the Amazon forest, atmospheric moisture flows from evapotranspiration to precipitation and the adaptation of the forest to annual precipitation and droughts (Fig. 1). Specifically, we combine a dynamical system model to represent empirically obtained forest tipping points with regard to mean annual precipitation (MAP) and drought intensity (MCWD: Maximum Cumulative Water Deficit). We assume that the forest is adapted to its local values of MAP and MCWD over 30 years. To account for possible spatial variability in the adaptation levels, we construct an ensemble of size 100 for each investigated year. We construct this moisture recycling network using output from Lagrangian atmospheric moisture tracking simulations and a global hydrological model (see methods)

We simulate a range of different future conditions, imposing average climatic conditions that resemble the conditions observed in each year from 2004 to 2014, during which the Amazon experienced two "droughts of a century" $(2005 \& 2010)^{39}$. We analyse Amazon rainforest cells as local-scale tipping elements of the moisture recycling network on a resolution of $1^{\circ} \times 1^{\circ}$ to assess their impact on the Amazon-wide system stability. Using this approach, we provide a bottom-up quantification of Amazon system stability, aiming to reveal where cascading effects of moisture recycling have the potential to induce domino effects in forest cover loss.

\section{Results}

Tipping due to drier conditions. To investigate a range of drought intensities and precipitation anomalies, we study the extent of the tipped area with respect to $\mathcal{Z}$-scores, which represent how many standard deviations the conditions are away from the mean across 1974-2003. We find a close correlation between $\mathcal{Z}_{\mathrm{MCWD}}$ and the tipped area, where a higher index reflects a larger tipped area (see Fig. 2a). The years 2005, 2007 and 2010, which are the years with the largest ENSO ONI indices $\frac{40}{4}$, show the largest tipped area. Overall, we find that the number of tipped 

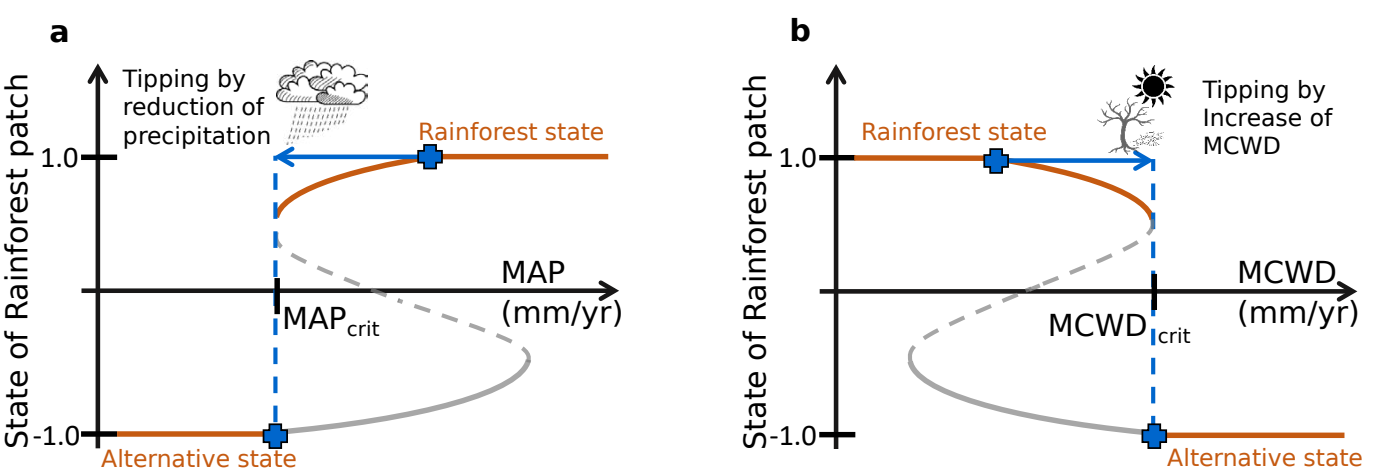

- Occupied state $\quad$ Unoccupied state $\quad$ - - Unstable state
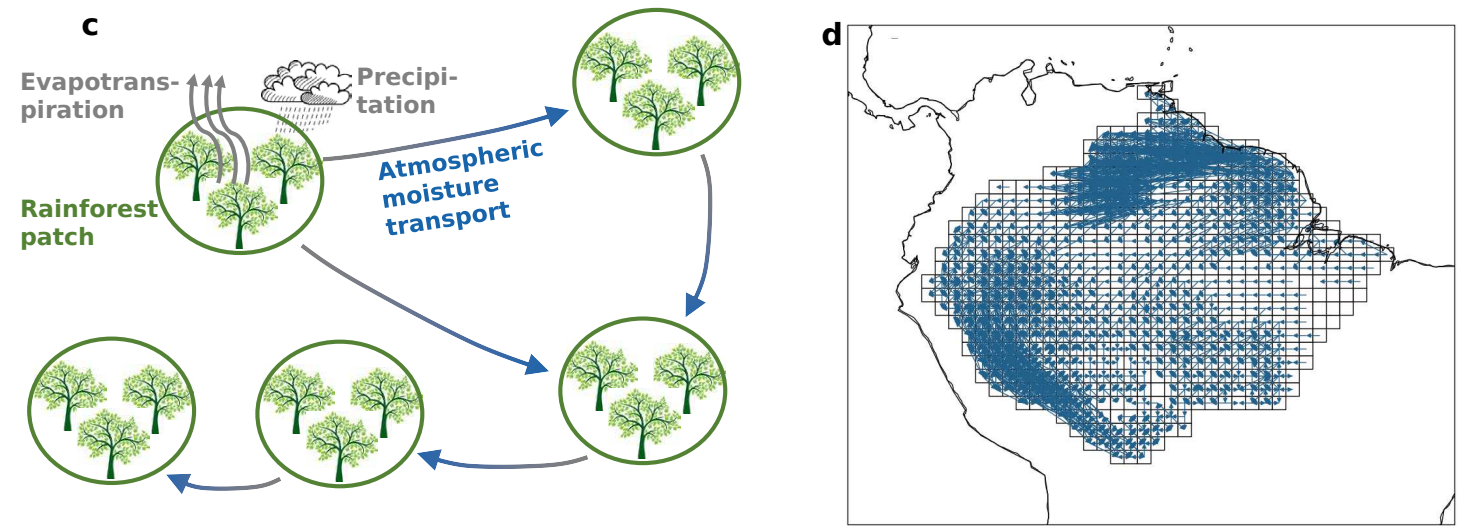

Figure 1 Nonlinear effects and moisture recycling network in the Amazon rainforest. a, Dynamical property of each $1^{\circ} \times 1^{\circ}$ cell of the rainforest depicted as state of rainforest cell (forest cover) versus MAP value. The state of the rainforest is limited by full forest cover (1.0) and no forest cover (-1.0). Between these two stable states, there is a tipping process as soon as the MAP value has fallen below its adaptation specific MAP $_{\text {crit }}$ value. Since we are focussing on drought triggered tipping events from forest to non-forest states in this study, each cell can only exist on the occupied states (brown), but not on the unoccupied states (grey). The blue arrow depicts a potential reduction in precipitation that is sufficient to trigger a tipping event in this specific cell. b, Same as in a for MCWD. c, Exemplary moisture recycling network: the rainforest cells are interconnected via a moisture recycling network due to precipitation and evapotranspiration. Through this mechanism effects of reduced tree cover can be promoted and tipping cascades are possible. d, Moisture recycling network for the hydrological year 2014 thresholded for links above $10 \mathrm{~mm} / \mathrm{yr}$ to remain visibility. In the simulation results, links above $1 \mathrm{~mm} / \mathrm{yr}$ are used. The dominant flow direction comes from the Atlantic ocean through easterly winds, reaches the Andes, and is then bend southward along the Andes. Moisture recycling links based on separate months can be found in Supplementary Figs. 1 and 2 comparing the year 2014 with the extreme drought year 2010. 
cells is significantly higher for the years 2005 and 2010 than for the other years (see Fig. 2 a). Both droughts have been termed a "once in a century drought" 41 . 2010 shows the highest vulnerability pattern, despite a lower $\mathcal{Z}_{\mathrm{MCWD}}$ index than for 2005 . The reason might be that the 2010 drought was spatially more extensive than the one in 2005 . In $2010,3.0 \times 10^{6} \mathrm{~km}^{2}$ versus $1.9 \times 10^{6} \mathrm{~km}^{2}$ in 2005 showed rainfall anomalies of one standard deviation less than during the decadal climatological mean ${ }^{35}$. From a tipping point of view, 2010 causes the highest vulnerabilities, whereas 2005 is the most extreme year from a rainfall (from oceanic background) perspective within our study period ${ }^{29}$. This suggests that the drought anomaly pattern is more important for the stability of the rainforest than the extremity of moisture inflow itself.

We separate tipping events into primarily induced tipping events from MAP or MCWD and secondary events from network effects (tipping cascades). Our model shows that between 10\% and $60 \%$ of the tipping is due to the cascading effects from the moisture recycling network depending on the drought strength (see network effects in Fig. $2 \mathrm{p}$ ). The cascading effect is especially strong for the years that show the strongest drought signatures $(2005,2007 \& 2010)$. This is probably due to the fact that many cells are shifted towards their tipping point and some of them over it. Then, in succession of this tipping and the subsequent further reduction of the moisture transport, many more cells in these years transgress their calculated threshold. In turn, if droughts intensify in the future, cascading tipping may increase disproportionally.

We also compared these results with the results of an only MAP-based normalised drought index $\mathcal{Z}_{\mathrm{MAP}}$ analogous to Eq. 2, but find no correlation between the tipped area and the MAP based index (see Supplementary Fig. 3).

Vulnerability maps. Over the course of the evaluated time span from 2004-2014, one region 

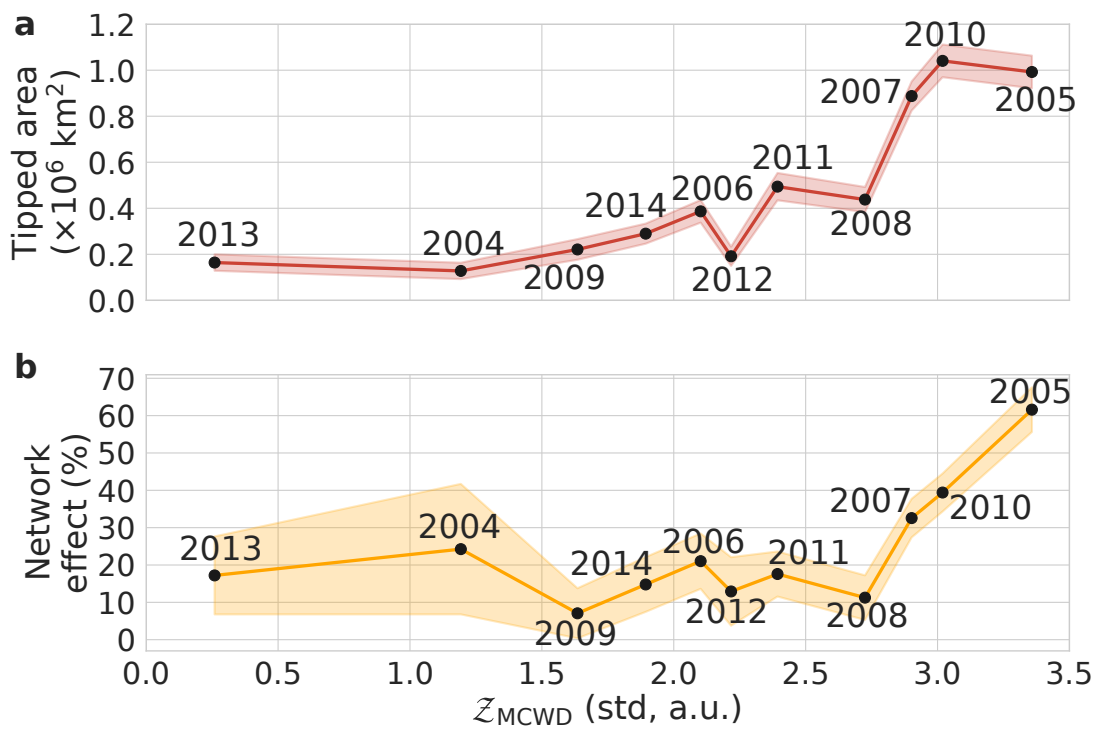

Figure $2 \mid$ Vulnerability of the rainforest against MCWD-based drought intensity. a, The total tipped area is shown over the course of the normalised drought index based on the MCWD $\mathcal{Z}$-score. The tipped area represents the number of tipped cells in the model where each $1^{\circ} \times 1^{\circ}$ cell has an area of approximately $\left(111 \mathrm{~km}^{2}\right) . \mathbf{b}$, The additional tipped area due to network effects for each year is shown in percentage of the tipped area in panel $\mathbf{a}$. This shows the effects of cascading transitions which are on the order of $10 \%$ to $60 \%$ depending on the evaluated hydrological year. The same analysis has been performed for a MAP based index, but no correlation was found (see Supplementary Fig. 3). 
shows increased patterns of vulnerability (see likelihood of vulnerability in Fig. 3a). This region is located in the southeastern Amazon, and caused by the combination of MCWD anomalies and network effects. As expected from Fig 2, the likelihood of the vulnerability patterns varies strongly from year to year (see Supplementary Fig. 4), but the vulnerable region in the southeast is a recurrent phenomenon across all years.

We investigate the vulnerable regions in detail since, in our model, small changes in the state already have an impact on the moisture recycling network, even though the respective cell does not tip. This can be realised if the environmental conditions shift a rainforest cell in our model close, but not over, its tipping point. Therefore, we define a shift towards the tipping point without an actual tipping event as the closeness to tipping. We find that this closeness to tipping is high in the southeast of the Amazon basin and in the subsequent dominant downwind direction towards the Andes. The largest average shifts towards the tipping point are located around and close to the most endangered region in the southeast (see Fig. 3). The reason is that these cells are already tipped in most cases and do not contribute to the average closeness to tipping (see Fig. $4 \mathrm{a}$ ), but that is expressed by the high variability among the ensemble members (see southeastern region in Fig. $4 \mathrm{~b}$ ).

Although tipping points are thresholds by definition, the effects on the Amazon forest-rainfall system already occur before MCWD or MAP reaches that point. Droughts, even if these do not cause tipping of the forest, can have significant impacts on photosynthesis and evapotranspiration that may last for years $\frac{42,43}{}$. A threshold-only model cannot account for these effects. In our model, however, evapotranspiration scales with distance to the tipping point. In other words, when a forest becomes drier it generates less evapotranspiration, an effect that may cascade through the system. Thus, even though our approach is conceptual, it allows us to identify which areas are most vulnerable to the invisible effect of the moisture recycling network. The magnitude of this effect is on the order of $20 \%$ for many regions apart from the central Amazon 

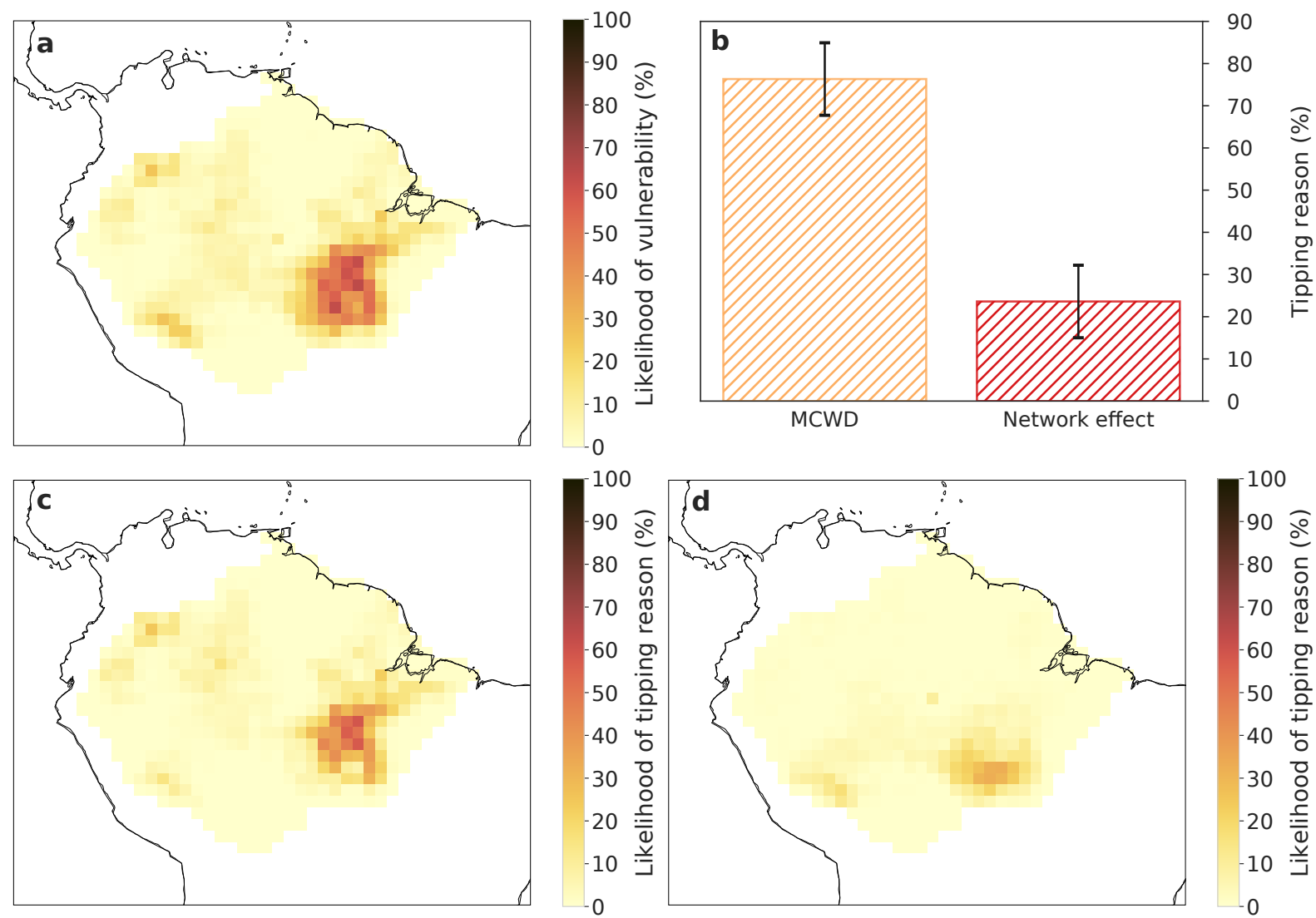

Figure 3 Vulnerable regions and tipping reason. a, The likelihood of tipping as an average over all ensemble members and all evaluated years from the hydrological years 2004 to 2014. The southeastern region is more vulnerable than other regions. In Supplementary Fig. 4, the yearly resolution results? can be found. b, Overall tipping reason averaged over the entire Amazon basin with error bars as the standard deviation over all years and all 100 ensemble members. A version separated into the future drought conditions from 2004 to 2014 can be found in Supplementary Fig. 5 for all these potential future drought scenarios. MAP does not contribute to tipping events (probability is less than $0.1 \%$ ) and is thus omitted from this figure. c, Tipping reason map: MCWD, d, Tipping reason map: Network (Cascading effects of the moisture recycling network). Note that panel $\mathbf{a}$ is the sum of the panels $\mathbf{c}$ and $\mathbf{d}$. 


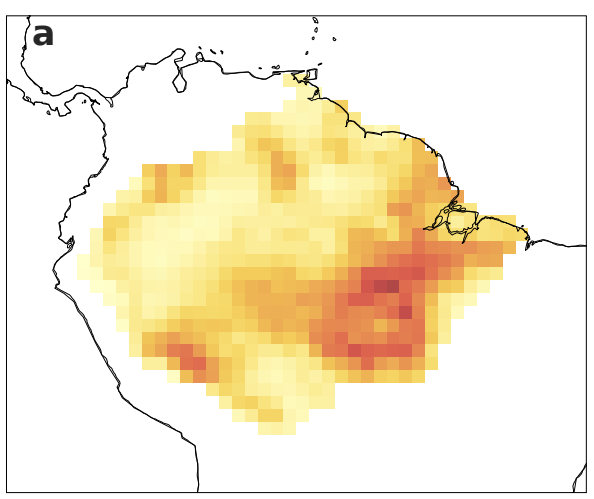
Amazon region (see Fig. 4 a).

and a small region in the very south of the Amazon. This represents an average evapotranspiration decrease of approximately $10 \%$ due to a shift towards the tipping point in the southeastern
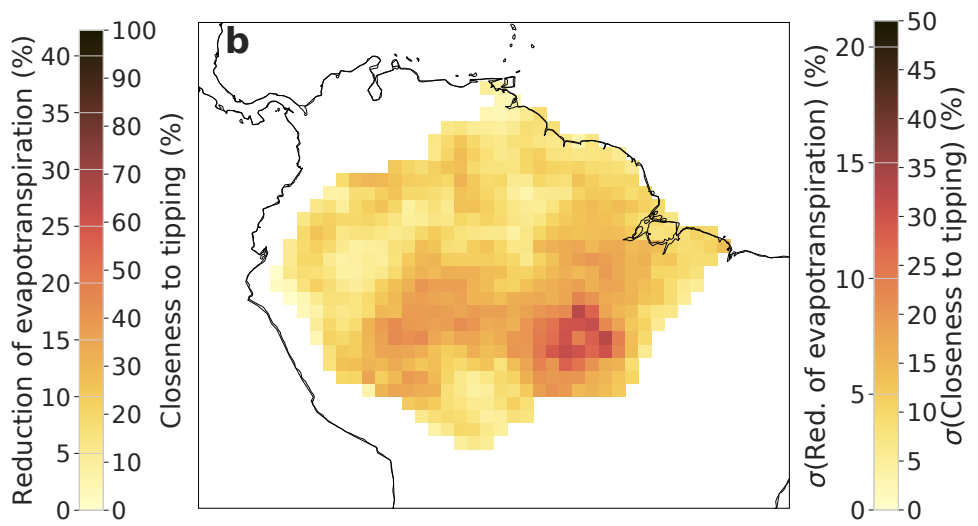

Figure 4 | Average shift towards the tipping point (Closeness to tipping). a, Mean shift to the tipping point as an average over all ensemble members. It can be seen that the shift is larger southern part of the Amazon rainforest such that these regions are the most vulnerable ones. $\mathbf{b}$, Standard deviation of a over all ensemble members. Note that cells are only accounted for if and only if the cell is not in the tipped regime in the respective simulation run. A second colour bar indicates the reduction of evapotranspiration due to changes in the state on average (panel a) together with its standard deviation (panel b). A version separated into the future conditions from 2004-2014 can be found in Supplementary Fig. 6.

The tipping reason and cascading effects. We reveal that, over the whole set of drought conditions, the direct effect of MCWD-induced tipping is prevalent $(76.3 \pm 8.5 \%)$ over the $23.6 \pm 8.5 \%$ that are due to cascading failure (see Fig. 3b). Moreover, transitions of the forest due to MAP as a primary reason are nearly completely negligible, they are responsible for less than $0.1 \%$ of all tipping events. On the other hand, the effect of cascading failure is considerably affecting the Amazon of up to a one-fourth of cells that tip additionally, on average, with large spread from year to year over the study period (see Supplementary Fig. 5).

The network effects are especially strong close to the region of direct MCWD-induced tipping 
and downwind from that (Fig. 3r, d). MCWD is the most important reason for tipping events in the southeast, whereas MAP is not responsible for many tipping events (see Fig. 3 a, b). Overall, the region in the southeast is vulnerable with respect to MCWD since this region has a relatively low interannual variability (standard deviation) of MCWD, while the intra-annual variability (mean) MCWD value is high (see Supplementary Fig. 7c, d).

\section{Discussion}

We estimate that tipping cascades may be responsible for around a one-fourth $(23.6 \pm 8.5 \%)$ of the tipping events in the Amazon rainforest following droughts. These cascades occur even when the forest is adapted to local climatic conditions. The reason is that drying is amplified by the moisture losses that result from such tipping. Loss of forest cover causes a reduction in evapotranspiration, which affects precipitation levels regionally. By constructing a dynamical network of forest cells connected by forest-induced moisture flows estimated from detailed atmospheric moisture flow simulations, we reveal how and where the Amazon is vulnerable to tipping cascade effects. Tipping due to fluctuating dry-season intensity (as measured by MCWD) is the dominant primary tipping reason $(76.3 \pm 8.5 \%)$ compared to fluctuations in annual rainfall. With a potential increase of future extreme drought events ${ }^{36 / 37,44}$, the average regional climate will be drier and some parts of the rainforest might thus be set under imminent risk of instability and could transgress into a less or non forest-covered state. We uncover that tipping events occur most frequently in southeastern Amazon (Fig. 3). This is also the region that is affected by three other factors. First, extended tipping cascades can be expected due to local interaction structures and reduced downwind moisture transport (Figs. 3 and 4). Second, it is also one of the regions located along the "arc of deforestation" and therefore already suffers from the pressure of human-induced activities, such as deforestation, ranching and extensive agriculture $^{45[46}$. And third, this region as well as the whole Amazon rainforest is threatened by 
road infrastructure projects ${ }^{4748449}$ and lack of environmental policies ${ }^{50151}$

In our study, we also find that potential future extreme drought conditions with a higher MCWD anomalies show a considerably larger tipped area. Cascading tipping events are more pronounced under these circumstances (Fig. 2). These are the drought conditions that can be expected from mid-century onwards if climate change progresses in a business-as-usual scenario ${ }^{37}$. The highest tipping signal in our model coincides with the strongest El-Niño ONI indices during the period 2004-2014 4 . It is known from the literature that El-Niño related droughts and other variability patterns affect the stability of the rainforest and tropical vegetation ${ }^{18|52| 53}$. If the anomalies associated El-Niño events intensify as projected by CMIP (Coupled

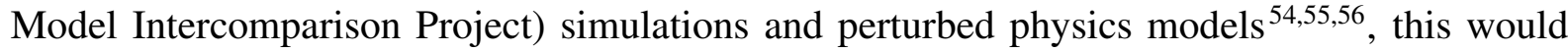
endanger substantial portions of the Amazon basin $\frac{57}{5}$. However, uncertainties remain whether strong El-Niño events might become more frequent in the future climate ${ }^{58}$.

Further human-induced changes such as deforestation also affect the evapotranspiration negatively which might then increase the frequency and severity of droughts together with ongoing climate change $\mathrm{S}^{30|33| 59 \mid 60}$. Overall, our results emphasise the relevance of the atmospheric moisture recycling network as an ecosystem service whose (partial) breakdown, combined with an increased number of climate-change induced extreme droughts, could trigger substantial changes across the Amazon basin.

Furthermore, moisture export supplies systems that are thousands of kilometres away, implying that forest-induced moisture export is an ecological service for regions beyond the Amazon rainforest itself. Altogether, preserving the Amazon and its ecological services are of utmost importance for local, regional and global climate stability. 


\section{Methods}

Data. The network was constructed using atmospheric moisture tracking simulations by Staal et al. $(2018)^{29}$. In that study, tree transpiration across South America during 2003-2014 was estimated and its atmospheric trajectories subsequently simulated using a Lagrangian atmospheric moisture tracking model with simulation time steps of 0.25 hours. The model output is on a monthly basis on $0.25^{\circ}$ resolution. Here, we reconstructed those simulation results by taking the moisture recycling ratios between $0.25^{\circ}$ grid cells, building monthly networks of moisture flows between each pair of cells of a certain resolution for the Amazon region and aggregating them to $1^{\circ} \times 1^{\circ}$ grid cells. In addition to tree transpiration, we also included interception evaporation from tree canopies, taken from Staal et al. (2020) varying monthly networks of forest-induced moisture flows across the Amazon. For details on the Lagrangian moisture tracking scheme, we refer to Staal et al. $(2018)^{29}$.

Monthly precipitation and evapotranspiration data for $2003-2014$ on $0.25^{\circ}$ resolution were taken from the Global Land Data Assimilation System (GLDAS) version 2.161. For 1974-2003 we used GLDAS2.0 since GLDAS2.1 data does not go back until 1974.

Note that all our simulations are based on hydrological years instead of calendar years due to the hydrological cycle over the Amazon basin.

Computation of MAP and MCWD. The mean annual precipitation (MAP) is derived from the monthly precipitation values for each cell. The MCWD index is here defined as the absolute value of the most negative value of cumulative water deficit (CWD) reached over a hydrological year 


$$
\begin{aligned}
& \mathrm{CWD}_{k}=\mathrm{CWD}_{k-1}+\text { Precipitation }_{k}-\text { Evaporation }_{k} \\
& \max \left(\mathrm{CWD}_{k}\right)=0 \\
& \operatorname{MCWD}=\operatorname{abs}\left(\min \left\{\mathrm{CWD}_{k}, \mathrm{CWD}_{k+1}, \ldots, \mathrm{CWD}_{k+12}\right\}\right),
\end{aligned}
$$

where $k$ is the number of the month in the hydrological year. We make use of the actual measured regional evaporation values, whereas other studies have chosen a fixed evaporation value of $100 \mathrm{~mm}$ in each month to compute MCWD 5 .35. We also resimulated all results with a fixed evaporation of $100 \mathrm{~mm} / \mathrm{month}$ and find that this leads to a decreased tipping due to MCWD. Thus, the southeastern region is less vulnerable to tipping, but the qualitative results are in agreement (see Supplementary Figs. 10d and 12.).

Computation of the $\mathcal{Z}$-score The $\mathcal{Z}$-score is used to find the ranges of future conditions that we are simulating in this work. We simulate ranges from current conditions up to extreme droughts that are 3.5 standard deviations away from the mean (see Fig. 2). The MCWD based $\mathcal{Z}$-score is computed by

$$
\mathcal{Z}_{\mathrm{MCWD}}=\frac{\operatorname{MCWD}(\text { year })-\mu_{\mathrm{MCWD}}}{\sigma_{\mathrm{MCWD}}}
$$

Here, $\mu_{\mathrm{MCWD}}$ and $\sigma_{\mathrm{MCWD}}$ are the average and standard deviation of the calibration period from 1974-2003. MCWD(year) is the average MCWD of the specific investigated year (see methods: Computation of MAP and MCWD). For comparison, the $\mathcal{Z}$-score based on MAP is computed (see Eq. 3) and plotted for comparison, but there is no relationship between tipped area and a higher MAP based score visible (see Supplementary Fig. 3):

$$
\mathcal{Z}_{\mathrm{MAP}}=\frac{\operatorname{MAP}(\text { year })-\mu_{\mathrm{MAP}}}{\sigma_{\mathrm{MAP}}} .
$$


Adaptation and computation of critical thresholds. For the purpose of computing local adaptation values, we use a calibration dataset from GLDAS from the hydrological years 1974 to 2003. From there, we compute the 30-year long term mean of MAP and MCWD values together with their standard deviations (see Supplementary Fig. 7). The critical value for MAP and MCWD where a state transition occurs is then computed for each grid cell $i$ as

$$
\begin{array}{r}
\operatorname{MAP}_{\text {crit }, i}=\mu_{\mathrm{MAP}, i}-\alpha_{i} \cdot \sigma_{\mathrm{MAP}, i} \\
\mathrm{MCWD}_{\text {crit }, i}=\mu_{\mathrm{MCWD}, i}+\alpha_{i} \cdot \sigma_{\mathrm{MCWD}, i} .
\end{array}
$$

$\mu_{i}$ is the mean, $\sigma_{i}$ the standard deviation of cell $i$ and $\alpha_{i}$ an adaptation factor that determines the exact value of the tipping point.

This procedure leads to the effect that regions with a high MAP as for instance in the central Amazon region can only be sustained at higher MAP values compared to other, typically drier regions as for instance in the south of the Amazon basin or close to the Andes region. The same arguments are valid for MCWD, with regional differences to MAP. Furthermore, higher variability, i.e., a higher standard deviation, in a region leads to higher adaptation percentage wise (training effect). In contrast to potential landscape methods as used in earlier studies ${ }^{17 / 32}$, this procedure has the advantage that it is able to specifically assess sustained periods of changing MAP and MCWD conditions on a local scale.

Dependence on adaption values. With our setting, we can now compute what would happen under sustained conditions that resembles the yearly conditions observed in a particular hydrological year of our study period from 2004 to 2014. In our experiments, we assume that each cell starts with full forest cover (state $=1.0$ ) at $t=0$. If we are taking, for instance the precipitation, evaporation and moisture recycling network of a certain year, then we will find some cells that are unstable since their MAP or, mostly, their MCWD value is below the critical value which is defined with the timeseries from 1974-2003 (see Supplementary Fig. 8). If this 
is the case, this cell transgresses its threshold and becomes forest cover free which then leads to reduced moisture recycling since the moisture transport value is multiplied by the fraction of forest cover. This means that the moisture transport value is set to zero when a forested cell tipped. This can then drive further cells towards or across their tipping point such that cascading events can be expected. In case a cell is only driven towards, but not over its tipping point, the effects on moisture recycling and tree cover are still accounted for assuming that the response of the vegetation is linearly represented by the state, instead of this effect being zero as in threshold-only models ${ }^{32}$.

The critical values depend on the level of local adaptation $\alpha_{i}$ (see Eq. (4). Thus, it can be expected that a higher adaptation factor leads to a lower number of tipped rainforest cells. In a calibration experiment for adaptation factors between 1.0 and 3.0 standard deviations and a constant adaptation factor for all cells $i\left(\alpha_{i}=\alpha \forall i\right)$, we find that the tipped area indeed goes down with increased adaptation factors (see Supplementary Fig. 9). The difference between experiments where we allow cascading effect (blue) and do not (red) is shown in green. In reality, the true value of adaptation of a certain cell is unknown and might vary from location to location. That is why a new ensemble of simulations with increased robustness is required and the constant adaptation factor hypothesis $\left(\alpha=\alpha_{i} \forall i\right)$ is dropped in favour of an ensemble approach where $\alpha_{i}$ is varied locally. Thus, we create an ensemble of 100 members for each year in the study period.

Construction of ensemble. Eq. 4 determines the critical values for MAP and MCWD for each $1^{\circ} \times 1^{\circ}$ cell separately. The critical value is dependent on the local average value as well as the variability of the 30 years before the study period (GLDAS data from 1974-2003). The exact critical value is determined by the adaptation factor $\alpha$ and must in turn be chosen appropriately. Therefore, we assume that a cell is on average able to remain in the same state under MAP 
and MCWD conditions that are two standard deviations away from their mean, i.e., from their "experiences" during the last 30 years. However, the exact value of adaptation is uncertain and might be different in different regions, also due to several factors that we do not model explicitly in this work. But we take this into account by drawing the individual adaptation values $\alpha_{i}$ for each cell $i$ from a $\beta$-distribution that is centred at 2 standard deviations and ranges from 1 to 3 standard deviations

$$
\beta(x, a, b)=\left(\sigma_{\text {upper }}-\sigma_{\text {lower }}\right) \cdot \frac{x^{a-1}(1-x)^{b-1}}{\int_{0}^{1} t^{a-1}(t-1)^{b-1} d t}+\sigma_{\text {lower }} .
$$

Here, we use $\sigma_{\text {upper }}=3.0$ and $\sigma_{\text {lower }}=1.0$ for the upper and lower bounds. We choose $a=b=2.5$ which ensures that, on average, $75 \%$ of all values lie between 1.5 to 2.5 standard deviations and $12.5 \%$ lie between 1.0 to 1.5 or between 2.5 to 3.0 standard deviations, respectively. This means that $75 \%$ lie in the central interval and $25 \%$ outside $(75-25-$ rule $)$. We have chosen a $\beta$-distribution since it is the analogy of a normal distribution for a fixed interval. With that procedure we construct an ensemble of 100 members of which three examples can be found in Supplementary Fig. 10. If not stated otherwise, all results shown are from the average over the 100 ensemble members.

Network of coupled nonlinear differential equations. We use a combination of nonlinear differential equations together with a complex network to describe the state of the rainforest cells and their interactions. We use this approach instead of a threshold approach since we want to be able to account for partial changes in the state and their effects on the network. For instance such changes can be critical for the tipping of cells that are not coupled directly, but via an intermediary cell, where partial changes are decisive for the emergence of a tipping cascade. Indirect effects have been found to account for $10 \%$ and more, already in very simple interaction structures in so called motifs ${ }^{62}$. 
In the differential equation approach in this work, we model the main hydrological parameters and the stability of the rainforest, but no further parameters such as biotic variables. The main hydrological properties are the precipitation (MAP), the MCWD and the moisture recycling. Following the reasoning above, we describe the mathematical details in the remainder of this section.

Each $1^{\circ} \times 1^{\circ}$ cell is represented by a differential equation of the form

$$
\frac{d x_{i}}{d t}=x_{i}^{3}-x_{i}+\mathcal{F}_{\text {crit }}\left(\mathrm{MAP}_{i}, \mathrm{MCWD}_{i}\right)
$$

where $x_{i}$ stands for the state of the rainforest cell and can be interpreted as the fraction of the tree cover. The shape of this function can be see in Supplementary Fig. 11. Furthermore, Eq. 6has the normal form of a saddle-node bifurcation and is a simple form of a differential equation with two stable states. Such equations have been suggested to model dynamics in various contexts such as economics, ecology or the Earth system ${ }^{6364655}$. The two states are stable depending on the value of the critical function $\mathcal{F}_{\text {crit }}$ where +1.0 stands for full tree cover and -1.0 for the alternative state without full tree cover. Such an alternative state could be a savanna like state or completely treeless. It is not possible for a cell to have lower tree cover values than $0 \%$ or values higher than full forest cover such that the state $x_{i}$ is limited to the interval $[-1.0,1.0]$. The advantage of choosing state limits of -1.0 and +1.0 is that the critical value then remains analytically representable and has the specific value $\mathcal{C}_{\text {crit }}=\sqrt{4 / 27}$ (see Supplementary Fig. 11). This value is derived from the discriminant of the polynomial of Eq. 6 and more details can be found in literature ${ }^{6466}$. For other state limits such as between 0.0 and 1.0, this would have to be dropped since the parameters in front of the cubic and linear terms of Eq. 6 would be different. Therefore, we decided for prefactors of 1.0 in front of the cubic and the linear term such that the state limits are -1.0 and +1.0 . As soon as the critical value of $\mathcal{C}_{\text {crit }}$ is reached 
by $\mathcal{F}_{\text {crit }}$ a state transition will occur since the upper stable state becomes unstable and only the lower stable state remains stable. For more details on this equation and the critical value, see e.g. Wunderling et al. (2020) or Klose et el. $(2020)^{62[64}$.

In our case, the rainforest cells are not independent, but interact via moisture recycling such that Eq. 6 becomes

$$
\frac{d x_{i}}{d t}=x_{i}^{3}-x_{i}+\mathcal{F}_{\text {crit }}\left(\operatorname{MAP}_{i}, \operatorname{MCWD}_{i}\right)+\sum_{\substack{j=1 \\ j \neq i}}^{N} \mathcal{M}_{j i}\left(\Delta \mathrm{MAP}_{j i}, \Delta \mathrm{MCWD}_{j i}\right) \frac{x_{j}}{2}
$$

Here, the entries of the critical matrix $\mathcal{M}_{j i}\left(\Delta \mathrm{MAP}_{j i}, \Delta \mathrm{MCWD}_{j i}\right)$ represent the strength of the moisture recycling link between two grid cells from $j$ to $i$. The state $x_{j}$ must be divided by 2 since the distance from minimum to maximum state is 2 . Similar forms of the network and the differential equation have already been used in earlier studies in the literature, but in a way more simplified form compared to this work ${ }^{62138}$.

Computation of the critical function. While the shape of each cell is represented by Eq. 6, the determination of the critical function with respect to MAP and MCWD remains. The critical function $\mathcal{F}_{\text {crit }}\left(\mathrm{MAP}_{i}, \mathrm{MCWD}_{i}\right)$ is computed in two steps. Firstly, for MAP

$$
\mathcal{F}_{\text {crit }}\left(\mathrm{MAP}_{i}\right)=\mathcal{C}_{\text {crit }} \cdot \frac{\mathrm{MAP}_{i}-\mu_{\mathrm{MAP}, \mathrm{i}}}{\mathrm{MAP}_{\text {crit }, \mathrm{i}}-\mu_{\mathrm{MAP}, \mathrm{i}}}
$$

where $\mu_{\mathrm{MAP}, \mathrm{i}}$ is the average value of that specific cell over the course of 30 years from the GLDAS calibration dataset (see Supplemenentary Figs. 6 and 7). The critical value MAP $_{\text {crit,i }}$ is also computed from this dataset using Eq. 4. $\mathrm{MAP}_{i}$ is the actual precipitation value in the cell within the evaluation period, for instance the value of the year 2010 in this cell for the case that the (drought) conditions of the year 2010 are investigated. Secondly, for MCWD

$$
\mathcal{F}_{\text {crit }}\left(\mathrm{MCWD}_{i}\right)=\mathcal{C}_{\text {crit }} \cdot \frac{\mathrm{MCWD}_{i}-\mu_{\mathrm{MCWD}, \mathrm{i}}}{\mathrm{MCWD}_{\text {crit }, \mathrm{i}}-\mu_{\mathrm{MCWD}, \mathrm{i}}}
$$


Although both equations (Eqs. 8 and 9) are in principle not limited, we restrict them to the interval $\left[0, \mathcal{C}_{\text {crit }}\right]$ since the critical value for tipping of Eq. 6 is reached at $\mathcal{C}_{\text {crit }}$ such that higher values are not necessary to tip a certain cell.

Then, the critical function $\mathcal{F}_{\text {crit }}\left(\mathrm{MAP}_{i}, \mathrm{MCWD}_{i}\right)$ is computed as

$$
\begin{array}{r}
\mathcal{F}_{\text {crit }}\left(\operatorname{MAP}_{i}, \operatorname{MCWD}_{i}\right)=\max \left\{\mathcal{F}_{\text {crit }}\left(\mathrm{MAP}_{i}\right), \mathcal{F}_{\text {crit }}\left(\mathrm{MCWD}_{i}\right)\right\}+ \\
+\left(1-\frac{\max \left\{\mathcal{F}_{\text {crit }}\left(\mathrm{MAP}_{i}\right), \mathcal{F}_{\text {crit }}\left(\mathrm{MCWD}_{i}\right)\right\}}{\mathcal{C}_{\text {crit }}}\right) \cdot \min \left\{\mathcal{F}_{\text {crit }}\left(\mathrm{MAP}_{i}\right), \mathcal{F}_{\text {crit }}\left(\mathrm{MCWD}_{i}\right)\right\}
\end{array}
$$

Again, the values of Eq. 10 are restricted to the interval $\left[0, \mathcal{C}_{\text {crit }}\right]$ since a state change occurs as soon as the upper value of the interval, i.e. $\mathcal{C}_{\text {crit }}$, is reached. The first term of Eq. 10 is sufficient to determine the critical function $\mathcal{F}_{\text {crit }}\left(\mathrm{MAP}_{i}, \mathrm{MCWD}_{i}\right)$ if $\mathcal{F}_{\text {crit }}\left(\mathrm{MAP}_{i}\right)$ or $\mathcal{F}_{\text {crit }}\left(\mathrm{MCWD}_{i}\right)$ are smaller than zero or larger than $\mathcal{C}_{\text {crit }}$. In case $\mathcal{F}_{\text {crit }}\left(\mathrm{MAP}_{i}\right)$ and $\mathcal{F}_{\text {crit }}\left(\mathrm{MCWD}_{i}\right)$ are larger than zero, but smaller than $\mathcal{C}_{\text {crit }}$, both terms of Eq. 10 are required. The second term takes the additional effect of the smaller of the two factors (from Eqs. 8 and 9 ) into account such that this is represented in the dynamics of Eq. 10. Then, partial state changes (even without tipping) affect the state of the rainforest cell and with that also the moisture recycling values (see curvature before tipping point in the sketch in Fig. $1 \mathrm{l}, \mathrm{b}$ ). This is an advantage of a fully dynamic model such as this, while threshold-only models would not be capable of doing this.

An example could be that $\mathcal{F}_{\text {crit }}\left(\mathrm{MAP}_{1}\right)=\mathcal{F}_{\text {crit }}\left(\mathrm{MAP}_{2}\right)=\frac{1}{2} \cdot \mathcal{C}_{\text {crit }}$ due to respective MAP values for two cells at the same time. Then it makes sense that the state of these two cells that have exactly this critical value with respect to MAP is not the same in case they have a different value with respect to their MCWD values. Let us assume that cell 1 has $\mathcal{F}_{\text {crit }}\left(\mathrm{MCWD}_{1}\right)=\frac{1}{4} \cdot \mathcal{C}_{\text {crit }}$ and cell 2 has $\mathcal{F}_{\text {crit }}\left(\mathrm{MCWD}_{2}\right)=\frac{1}{16} \cdot \mathcal{C}_{\text {crit }}$. Then, the second term of Eq. 10 takes these differences between the cells 1 and 2 into account shifting cell 1 a bit closer to its tipping point than cell 2 such that the reduction effect on the respective outgoing moisture recycling links is stronger for cell 1 than for cell 2 . 
Computation of the critical matrix. In analogy to Eqs. 8 and 9 , we define the critical matrix for MAP as

$$
\mathcal{M}_{j i}\left(\Delta \mathrm{MAP}_{j i}\right)=\mathcal{C}_{\text {crit }} \cdot \frac{\Delta \mathrm{MAP}_{j i}}{\mathrm{MAP}_{\text {crit,i }}-\mu_{\mathrm{MAP}, \mathrm{i}}}:=\mathcal{M}_{j i, \mathrm{MAP}}
$$

where $\triangle \mathrm{MAP}_{j i}$ represents the difference of the mean annual precipitation arising from the moisture recycling link $\delta_{j i}$ from cell $j$ to cell $i$. Thus: $\Delta \mathrm{MAP}_{j i}=\Delta \mathrm{MAP}\left(\delta_{j i}\right)=\delta_{j i}$ MAP.

For MCWD we have

$$
\mathcal{M}_{j i}\left(\Delta \mathrm{MCWD}_{j i}\right)=\mathcal{C}_{\text {crit }} \cdot \frac{\Delta \mathrm{MCWD}_{j i}}{\mathrm{MCWD}_{\text {crit,i }}-\mu_{\mathrm{MCWD}, \mathrm{i}}}:=\mathcal{M}_{j i, \mathrm{MCWD}}
$$

where $\triangle \mathrm{MCWD}_{j i}=\Delta \mathrm{MCWD}\left(\delta_{j i, \mathrm{MAP}}\right)$ is the potential increase of MCWD in response to

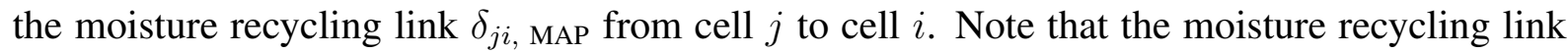
$\delta_{j i, \text { MAP }}$ can reduce the precipitation, while the evaporation (which also goes into the computation of the MCWD value, see Eq. 1) remains constant.

Then, analogously to Eq. 10 , the complete critical matrix is computed as

$$
\mathcal{M}_{j i}\left(\Delta \mathrm{MAP}_{j i}, \Delta \mathrm{MCWD}_{j i}\right)=\mathcal{M}_{j i, \mathrm{MAP}}+\left(1-\frac{\mathcal{M}_{j i, \mathrm{MAP}}}{\mathcal{C}_{\text {crit }}}\right) \cdot \mathcal{M}_{j i, \mathrm{MCWD}}
$$

if $\mathcal{F}_{\text {crit }}\left(\mathrm{MAP}_{i}\right)>\mathcal{F}_{\text {crit }}\left(\mathrm{MCWD}_{i}\right)$ or

$$
\mathcal{M}_{j i}\left(\Delta \mathrm{MAP}_{j i}, \Delta \mathrm{MCWD}_{j i}\right)=\mathcal{M}_{j i, \mathrm{MCWD}}+\left(1-\frac{\mathcal{M}_{j i, \mathrm{MCWD}}}{\mathcal{C}_{\text {crit }}}\right) \cdot \mathcal{M}_{j i, \mathrm{MAP}}
$$

if $\mathcal{F}_{\text {crit }}\left(\mathrm{MAP}_{i}\right)<\mathcal{F}_{\text {crit }}\left(\mathrm{MCWD}_{i}\right)$

Resolution independence. To check for robustness of our results, we recomputed our simulations with respect to the finer and coarser resolutions of $0.5^{\circ} \times 0.5^{\circ}, 1.5^{\circ} \times 1.5^{\circ}$ and $2^{\circ} \times 2^{\circ}$ (see Supplementary Figs. 10 and 12). For that purpose, we scale the minimal moisture recycling 
value connecting to rainforest cells with the area of a cell. In case of a resolution of $0.5^{\circ} \times 0.5^{\circ}$ we take all moisture recycling values of more than $0.25 \mathrm{~mm} / \mathrm{yr}$ into account, for $1^{\circ} \times 1^{\circ}$ we take all values above $1.0 \mathrm{~mm} / \mathrm{yr}$ into account, for $1.5^{\circ} \times 1.5^{\circ}$ all values above $2.25 \mathrm{~mm} / \mathrm{yr}$ and for $2^{\circ} \times 2^{\circ}$ all values above $4.0 \mathrm{~mm} / \mathrm{yr}$. Overall, we find that the vulnerability patterns are at the same location in the southeast (compare Fig. 3a with Supplementary Fig. 12a, b, c). Thus, the qualitative pattern is the same. The absolute values also show a close quantitative match within their standard deviations for resolutions of $1^{\circ} \mathrm{x} 1^{\circ}$ or coarser (see Supplementary Fig. 13a, b). The finer the resolution is, the higher the tipped area tendentially is. This is due to the fact that a higher resolution resolves cells to a finer level. These cells are then able to tip individually, whereas on a coarser resolution these cells are subsumed under one cell which is then still stable. Also, the scaling of the moisture recycling connections that we take into account might play a role for the increased tipping when the resolution becomes finer. Further note that we decreased the ensemble size for the resolution of $0.5^{\circ} \times 0.5^{\circ}$ from 100 to 10 ensemble members due to computational constraints.

Notes on colour maps. This paper makes use of perceptually uniform colour maps developed by F. Crameri 67 .

Data and Code availability. The data and code that support the findings of this study are available from the corresponding authors upon reasonable request. 


\section{References and Notes}

[1] Barlow, J. et al. The future of hyperdiverse tropical ecosystems. Nature 559, 517-526 (2018).

[2] Mitchard, E. T. The tropical forest carbon cycle and climate change. Nature 559, 527-534 (2018).

[3] Jenkins, C. N., Pimm, S. L. \& Joppa, L. N. Global patterns of terrestrial vertebrate diversity and conservation. Proceedings of the National Academy of Sciences 110, E2602E2610 (2013).

[4] Nobre, C. A. et al. Land-use and climate change risks in the amazon and the need of a novel sustainable development paradigm. Proceedings of the National Academy of Sciences 113, 10759-10768 (2016).

[5] Malhi, Y. et al. Exploring the likelihood and mechanism of a climate-change-induced dieback of the amazon rainforest. Proceedings of the National Academy of Sciences 106, 20610-20615 (2009).

[6] Malhi, Y. et al. Climate change, deforestation, and the fate of the amazon. science 319, 169-172 (2008).

[7] Salazar, L. F. \& Nobre, C. A. Climate change and thresholds of biome shifts in amazonia. Geophysical Research Letters 37 (2010).

[8] Oyama, M. D. \& Nobre, C. A. A new climate-vegetation equilibrium state for tropical south america. Geophysical research letters 30 (2003).

[9] Staver, A. C., Archibald, S. \& Levin, S. A. The global extent and determinants of savanna and forest as alternative biome states. Science 334, 230-232 (2011). 
[10] Hirota, M., Holmgren, M., Van Nes, E. H. \& Scheffer, M. Global resilience of tropical forest and savanna to critical transitions. Science 334, 232-235 (2011).

[11] Staal, A., Dekker, S. C., Hirota, M. \& van Nes, E. H. Synergistic effects of drought and deforestation on the resilience of the south-eastern amazon rainforest. Ecological Complexity 22, 65-75 (2015).

[12] van Nes, E. H., Hirota, M., Holmgren, M. \& Scheffer, M. Tipping points in tropical tree cover: linking theory to data. Global change biology 20, 1016-1021 (2014).

[13] Meir, P. et al. Threshold responses to soil moisture deficit by trees and soil in tropical rain forests: insights from field experiments. BioScience 65, 882-892 (2015).

[14] Lenton, T. M. et al. Tipping elements in the earth's climate system. Proceedings of the national Academy of Sciences 105, 1786-1793 (2008).

[15] Lovejoy, T. E. \& Nobre, C. Amazon tipping point: Last chance for action (2019).

[16] Lenton, T. M. et al. Climate tipping points—too risky to bet against (2019).

[17] Ciemer, C. et al. Higher resilience to climatic disturbances in tropical vegetation exposed to more variable rainfall. Nature Geoscience 12, 174-179 (2019).

[18] Holmgren, M., Hirota, M., Van Nes, E. H. \& Scheffer, M. Effects of interannual climate variability on tropical tree cover. Nature Climate Change 3, 755-758 (2013).

[19] Fu, R. et al. Increased dry-season length over southern amazonia in recent decades and its implication for future climate projection. Proceedings of the National Academy of Sciences 110, 18110-18115 (2013). 
[20] Dubreuil, V., Debortoli, N., Funatsu, B., Nédélec, V. \& Durieux, L. Impact of land-cover change in the southern amazonia climate: a case study for the region of alta floresta, mato grosso, brazil. Environmental monitoring and assessment 184, 877-891 (2012).

[21] Marengo, J. A. et al. Changes in climate and land use over the amazon region: current and future variability and trends. Frontiers in Earth Science 6, 228 (2018).

[22] Boisier, J. P., Ciais, P., Ducharne, A. \& Guimberteau, M. Projected strengthening of amazonian dry season by constrained climate model simulations. Nature Climate Change 5, 656-660 (2015).

[23] Joetzjer, E., Douville, H., Delire, C. \& Ciais, P. Present-day and future amazonian precipitation in global climate models: Cmip5 versus cmip3. Climate Dynamics 41, 2921-2936 (2013).

[24] Sakschewski, B. et al. Resilience of amazon forests emerges from plant trait diversity. Nature Climate Change 6, 1032-1036 (2016).

[25] Sakschewski, B. et al. Variable tree rooting strategies improve tropical productivity and evapotranspiration in a dynamic global vegetation model. Biogeosciences Discussions in review (2020).

[26] Choat, B. et al. Global convergence in the vulnerability of forests to drought. Nature 491, $752-755$ (2012).

[27] Aragão, L. E. Environmental science: The rainforest's water pump. Nature 489, 217-218 (2012).

[28] Eltahir, E. A. \& Bras, R. L. Precipitation recycling in the amazon basin. Quarterly Journal of the Royal Meteorological Society 120, 861-880 (1994). 
[29] Staal, A. et al. Forest-rainfall cascades buffer against drought across the amazon. Nature Climate Change 8, 539-543 (2018).

[30] Staal, A. et al. Feedback between drought and deforestation in the amazon. Environmental Research Letters 15, 044024 (2020).

[31] Zemp, D. et al. On the importance of cascading moisture recycling in south america. Atmospheric Chemistry and Physics (2014).

[32] Zemp, D. C. et al. Self-amplified amazon forest loss due to vegetation-atmosphere feedbacks. Nature Communications 8, 1-10 (2017).

[33] Boers, N., Marwan, N., Barbosa, H. M. \& Kurths, J. A deforestation-induced tipping point for the south american monsoon system. Scientific reports 7, 41489 (2017).

[34] Anderson, L. O. et al. Vulnerability of amazonian forests to repeated droughts. Philosophical Transactions of the Royal Society B: Biological Sciences 373, 20170411 (2018).

[35] Lewis, S. L., Brando, P. M., Phillips, O. L., van der Heijden, G. M. \& Nepstad, D. The 2010 amazon drought. Science 331, 554-554 (2011).

[36] Duffy, P. B., Brando, P., Asner, G. P. \& Field, C. B. Projections of future meteorological drought and wet periods in the amazon. Proceedings of the National Academy of Sciences 112, 13172-13177 (2015).

[37] Cox, P. M. et al. Increasing risk of amazonian drought due to decreasing aerosol pollution. Nature 453, 212-215 (2008).

[38] Krönke, J. et al. Dynamics of tipping cascades on complex networks. Physical Review E 101, 042311 (2020). 
[39] Marengo, J. A., Tomasella, J., Alves, L. M., Soares, W. R. \& Rodriguez, D. A. The drought of 2010 in the context of historical droughts in the amazon region. Geophysical Research Letters 38 (2011).

[40] NOAA - Climate Prediction Center - ONI. https://origin.cpc.ncep.noaa. gov/products/analysis_monitoring/ensostuff/ONI_v5.php (2020).

[41] Marengo, J. A. \& Espinoza, J. C. Extreme seasonal droughts and floods in amazonia: causes, trends and impacts. International Journal of Climatology 36, 1033-1050 (2016).

[42] Maeda, E. E., Kim, H., Aragão, L. E., Famiglietti, J. S. \& Oki, T. Disruption of hydroecological equilibrium in southwest amazon mediated by drought. Geophysical Research Letters 42, 7546-7553 (2015).

[43] Restrepo-Coupe, N. et al. What drives the seasonality of photosynthesis across the amazon basin? a cross-site analysis of eddy flux tower measurements from the brasil flux network. Agricultural and Forest Meteorology 182, 128-144 (2013).

[44] Aragao, L. E. et al. Environmental change and the carbon balance of a mazonian forests. Biological Reviews 89, 913-931 (2014).

[45] Pereira, E. J. d. A. L., de Santana Ribeiro, L. C., da Silva Freitas, L. F. \& de Barros Pereira, H. B. Brazilian policy and agribusiness damage the amazon rainforest. Land Use Policy 92, $104491(2020)$.

[46] Davidson, E. A. et al. The amazon basin in transition. Nature 481, 321-328 (2012).

[47] Ferrante, L. \& Fearnside, P. M. The amazon's road to deforestation. Science 369, 634-634 (2020). 
[48] dos Santos Júnior, M. et al. Br-319 como propulsora de desmatamento: Simulando o impacto da rodovia manaus-porto velho. Instituto do Desenvolvimento Sustentável da Amazônia [in portuguese] (2018).

[49] Pfaff, A. et al. Road investments, spatial spillovers, and deforestation in the brazilian amazon. Journal of regional Science 47, 109-123 (2007).

[50] Diele-Viegas, L. M., Pereira, E. J. d. A. L. \& Rocha, C. F. D. The new brazilian gold rush: Is amazonia at risk? Forest Policy and Economics 119, 102270 (2020).

[51] Artaxo, P. Working together for amazonia. Science 363, 323 (2019).

[52] Holmgren, M. et al. Extreme climatic events shape arid and semiarid ecosystems. Frontiers in Ecology and the Environment 4, 87-95 (2006).

[53] Malhi, Y. \& Wright, J. Spatial patterns and recent trends in the climate of tropical rainforest regions. Philosophical Transactions of the Royal Society of London. Series B: Biological Sciences 359, 311-329 (2004).

[54] Cai, W. et al. Enso and greenhouse warming. Nature Climate Change 5, 849-859 (2015).

[55] Cai, W. et al. Increasing frequency of extreme el niño events due to greenhouse warming. Nature Climate Change 4, 111-116 (2014).

[56] Timmermann, A. et al. Increased el niño frequency in a climate model forced by future greenhouse warming. Nature 398, 694-697 (1999).

[57] Duque-Villegas, M., Salazar, J. F. \& Rendón, A. M. Tipping the enso into a permanent el niño can trigger state transitions in global terrestrial ecosystems. Earth System Dynamics 10 (2019). 
[58] Collins, M. et al. The impact of global warming on the tropical pacific ocean and el niño. Nature Geoscience 3, 391-397 (2010).

[59] Chambers, J. Q. \& Artaxo, P. Biosphere-atmosphere interactions: Deforestation size influences rainfall. Nature Climate Change 7, 175-176 (2017).

[60] D'Almeida, C. et al. The effects of deforestation on the hydrological cycle in amazonia: a review on scale and resolution. International Journal of Climatology: A Journal of the Royal Meteorological Society 27, 633-647 (2007).

[61] Rodell, M. et al. The global land data assimilation system. Bulletin of the American Meteorological Society 85, 381-394 (2004).

[62] Wunderling, N. et al. How motifs condition critical thresholds for tipping cascades in complex networks: Linking micro-to macro-scales. Chaos: An Interdisciplinary Journal of Nonlinear Science 30, 043129 (2020).

[63] Wunderling, N., Donges, F. J., Kurths, J. \& Winkelmann, R. Interacting tipping elements increase risk of climate domino effects under global warming. Earth Syst. Dynam. Discuss. (in review) (2020).

[64] Klose, A. K., Karle, V., Winkelmann, R. \& Donges, J. F. Emergence of cascading dynamics in interacting tipping elements of ecology and climate. Royal Society Open Science 7, 200599 (2020).

[65] Brummitt, C. D., Barnett, G. \& D’Souza, R. M. Coupled catastrophes: sudden shifts cascade and hop among interdependent systems. Journal of The Royal Society Interface 12, $20150712(2015)$. 
[66] Kuznetsov, Y. A. Elements of Applied Bifurcation Theory, Applied Mathematical Sciences, vol. 112 (Springer Science \& Business Media, New York, 2004).

[67] Crameri, F. Geodynamic diagnostics, scientific visualisation and staglab 3.0. Geoscientific Model Development 11, 2541-2562 (2018). 


\section{Acknowledgements}

We are thankful to Kirsten Thonicke and Markus Drüke for fruitful discussions. This work has been carried out within the framework of PIK's FutureLab on Earth Resilience in the Anthropocene. N.W. and R.W. acknowledge the financial support of the IRTG 1740/TRP 2015/501220 project funded by DFG and FAPESP. N.W. is grateful for a scholarship from the Studienstiftung des deutschen Volkes. N.W., J.F.D. and R.W. are thankful for financial support by the Leibniz Association (project DominoES). A.S. and J.F.D. acknowledge support from the European Research Council Advanced Grant project ERA (Earth Resilience in the Anthropocene, ERC-2016-ADG-743080). A.S. and O.A.T. thank for support from the Bolin Centre for Climate Research. B.S. acknowledges funding from the BMBF- and Belmont Forum-funded project “CLIMAX: Climate services through knowledge co-production: A Euro-South American initiative for strengthening societal adaptation response to extreme events", FKZ 01LP1610A. M.H. is supported by a grant from Instituto Serrapilheira/Serra-1709-18983. O.A.T. acknowledges funding from the Netherlands Organisation for Scientific Research Innovational Research Incentives Schemes VENI (016.171.019). J.F.D. is grateful for financial support by the Stordalen Foundation via the Planetary Boundary Research Network (PB.net) and the Earth League's EarthDoc program. H.B. was supported by research grants 2015/50122-0 and 2016/188662, São Paulo Research Foundation (FAPESP); and grant 308682/2017-3, Brazilian National Research Council (CNPq). The authors gratefully acknowledge the European Regional Development Fund (ERDF), the German Federal Ministry of Education and Research and the Land Brandenburg for supporting this project by providing resources on the high performance computer system at the Potsdam Institute for Climate Impact Research.

\section{Author contributions}

N.W., J.F.D, H.B. and R.W. designed the study. N.W. conducted the model simulation runs 
601

602

606

607

608

and prepared the figures. N.W. and A.S. led the writing of the manuscript with input from all authors. A.S. and O.A.T. developed the moisture recycling dataset of the Amazon rainforest. H.B. and R.W. jointly supervised this study.

\section{Additional information}

Supplementary information is available in the online version of the paper. Reprints and permissions information are available online at www.nature.com/reprints. Requests for materials should be addressed to N.W.

\section{Competing interests}

The authors declare no competing interests. 


\section{Figures}
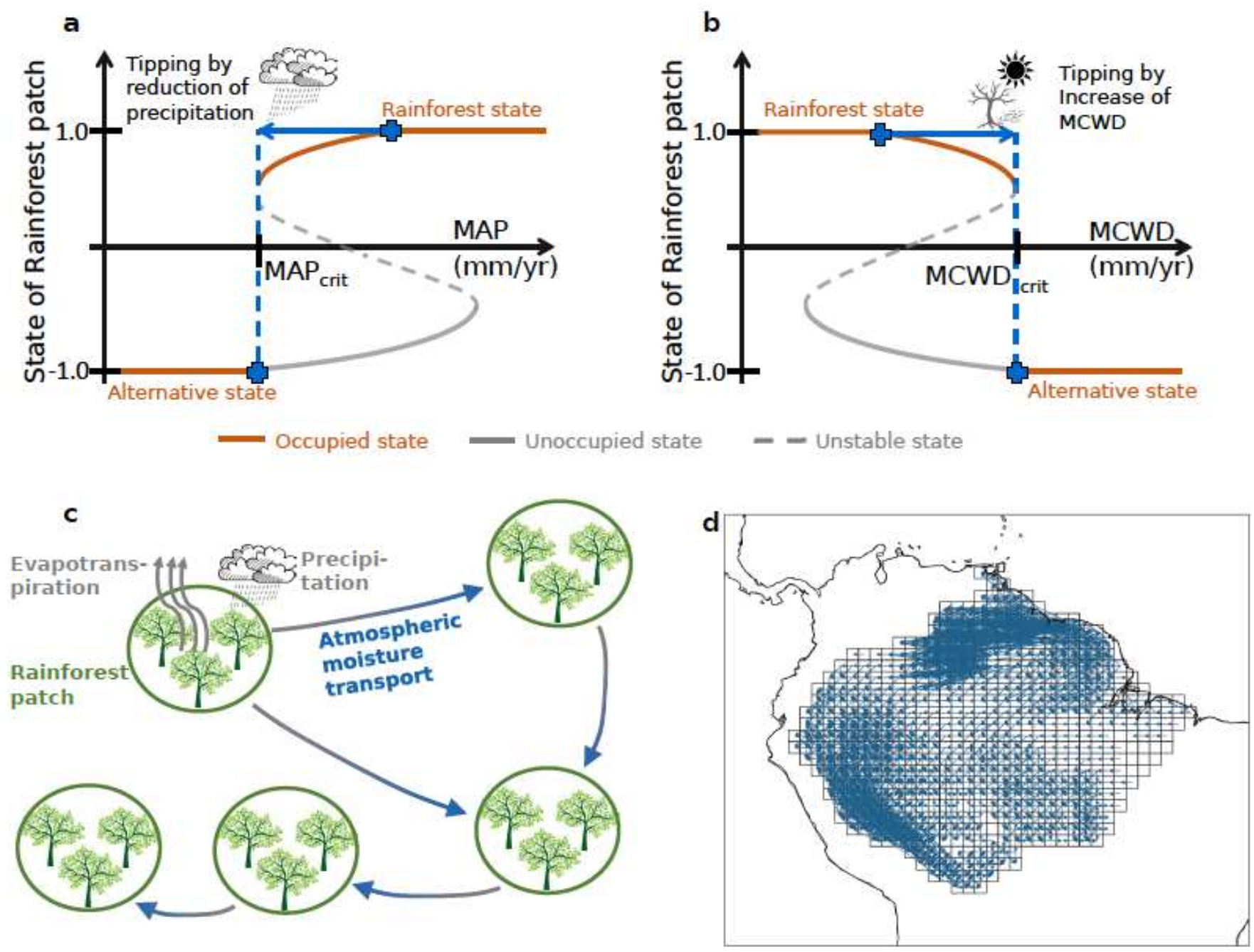

\section{Figure 1}

Nonlinear effects and moisture recycling network in the Amazon rainforest. a, Dynamical property of each $1^{\circ} \nabla \times 1^{\circ} \nabla$ cell of the rainforest depicted as state of rainforest cell (forest cover) versus MAP value. The state of the rainforest is limited by full forest cover (1.0) and no forest cover (-1.0). Between these two stable states, there is a tipping process as soon as the MAP value has fallen below its adaptation specific MAPcrit value. Since we are focussing on drought triggered tipping events from forest to non-forest states in this study, each cell can only exist on the occupied states (brown), but not on the unoccupied states (grey). The blue arrow depicts a potential reduction in precipitation that is sufficient to trigger a tipping event in this specific cell. b, Same as in a for MCWD. c, Exemplary moisture recycling network: the rainforest cells are interconnected via a moisture recycling network due to precipitation and evapotranspiration. Through this mechanism effects of reduced tree cover can be promoted and tipping cascades are possible. d, Moisture recycling network for the hydrological year 2014 thresholded for links 
above $10 \mathrm{~mm} / \mathrm{yr}$ to remain visibility. In the simulation results, links above $1 \mathrm{~mm} / \mathrm{yr}$ are used. The dominant flow direction comes from the Atlantic ocean through easterly winds, reaches the Andes, and is then bend southward along the Andes. Moisture recycling links based on separate months can be found in Supplementary Figs. 1 and 2 comparing the year 2014 with the extreme drought year 2010.
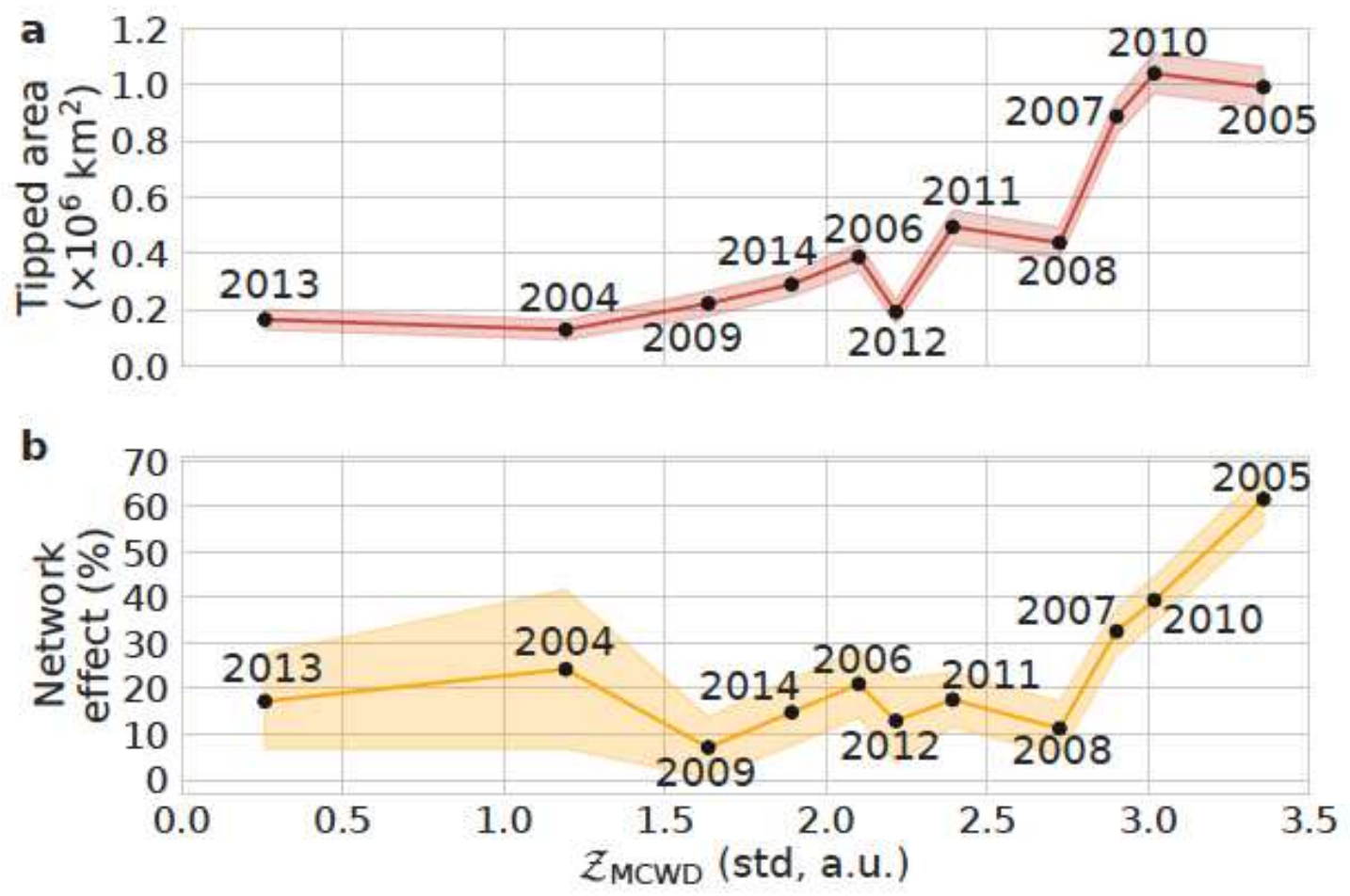

\section{Figure 2}

Vulnerability of the rainforest against MCWD-based drought intensity. a, The total tipped area is shown over the course of the normalised drought index based on the MCWD Z-score. The tipped area represents

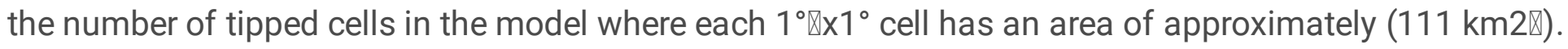
$\mathrm{b}$, The additional tipped area due to network effects for each year is shown in percentage of the tipped area in panel a. This shows the effects of cascading transitions which are on the order of $10 \%$ to $60 \%$ depending on the evaluated hydrological year. The same analysis has been performed for a MAP based index, but no correlation was found (see Supplementary Fig. 3). 

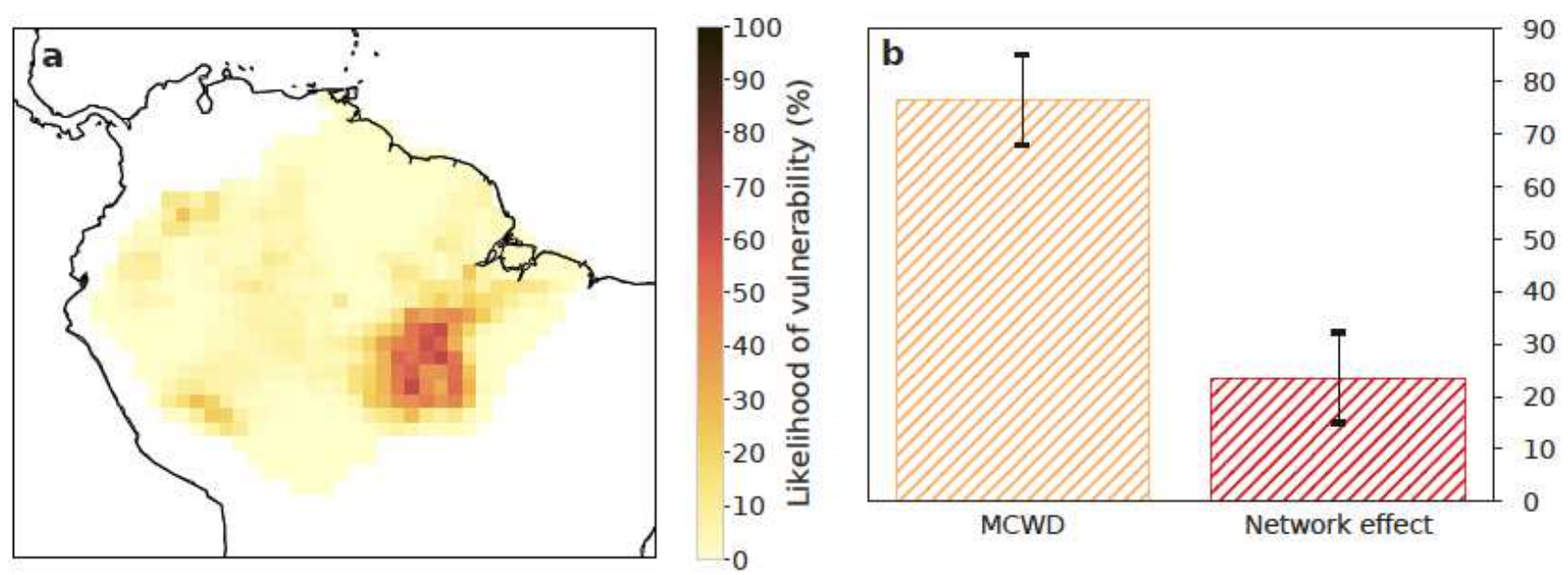

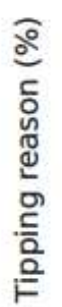
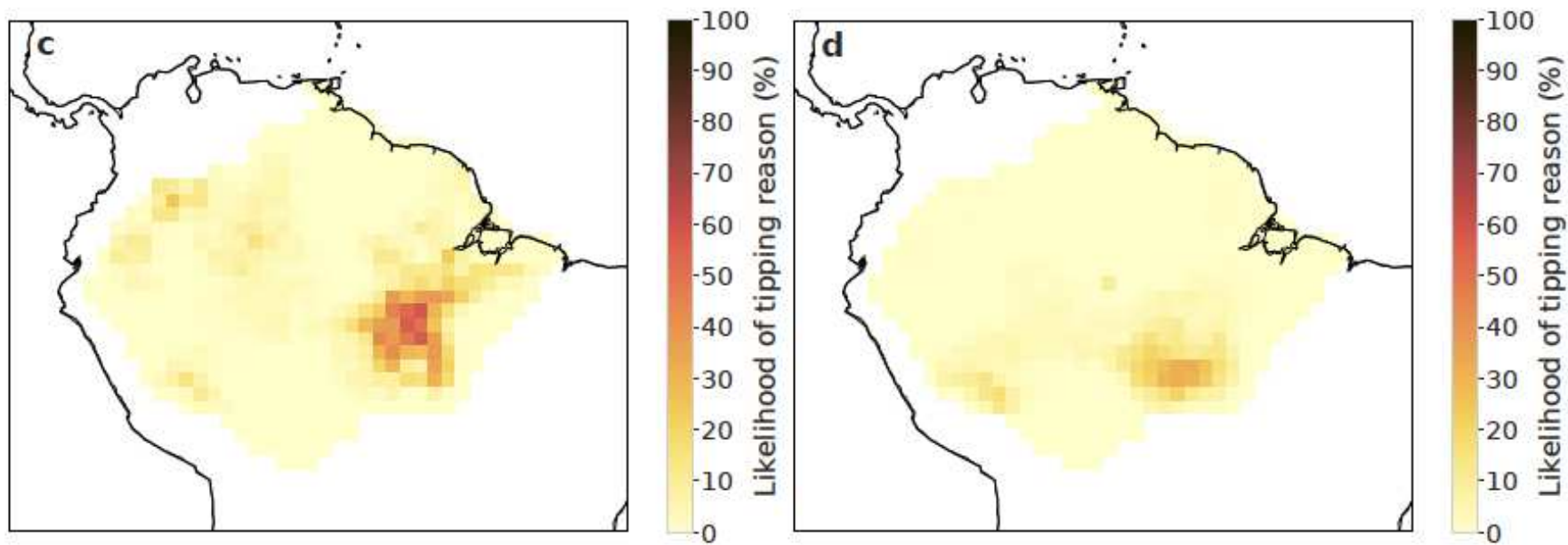

\section{Figure 3}

Vulnerable regions and tipping reason. a, The likelihood of tipping as an average over all ensemble members and all evaluated years from the hydrological years 2004 to 2014 . The southeastern region is more vulnerable than other regions. In Supplementary Fig. 4, the yearly resolution results? can be found. b, Overall tipping reason averaged over the entire Amazon basin with error bars as the standard deviation over all years and all 100 ensemble members. A version separated into the future drought conditions from 2004 to 2014 can be found in Supplementary Fig. 5 for all these potential future drought scenarios. MAP does not contribute to tipping events (probability is less than $0.1 \%$ ) and is thus omitted from this figure. c, Tipping reason map: MCWD, d, Tipping reason map: Network (Cascading effects of the moisture recycling network). Note that panel $\mathrm{a}$ is the sum of the panels $\mathrm{c}$ and $\mathrm{d}$. 

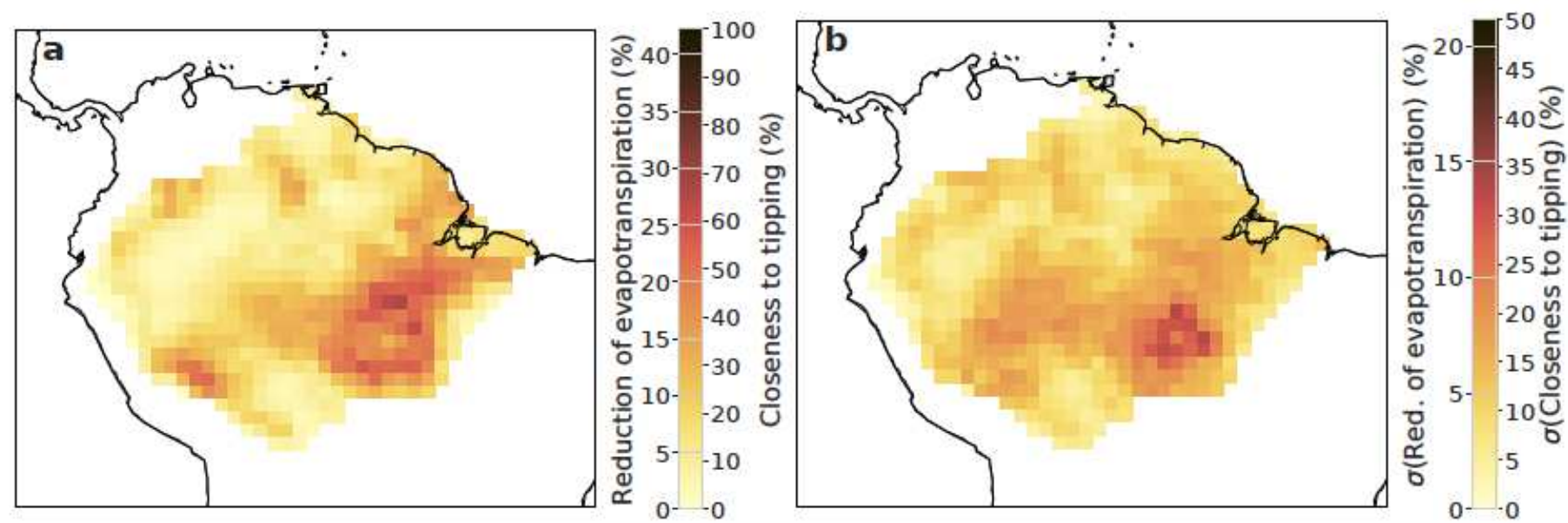

Figure 4

Average shift towards the tipping point (Closeness to tipping). a, Mean shift to the tipping point as an average over all ensemble members. It can be seen that the shift is larger southern part of the Amazon rainforest such that these regions are the most vulnerable ones. b, Standard deviation of a over all ensemble members. Note that cells are only accounted for if and only if the cell is not in the tipped regime in the respective simulation run. A second colour bar indicates the reduction of evapotranspiration due to changes in the state on average (panel a) together with its standard deviation (panel b). A version separated into the future conditions from 2004-2014 can be found in Supplementary Fig. 6.

\section{Supplementary Files}

This is a list of supplementary files associated with this preprint. Click to download.

- Supplement.pdf 